\title{
Gout is associated with an increased risk for incident heart failure among older adults: the REasons for Geographic And Racial Differences in Stroke (REGARDS) cohort study
}

Lisandro D. Colantonio ${ }^{1 *}$, Kenneth G. Saag ${ }^{2}$, Jasvinder A. Singh ${ }^{1,2,3}$, Ligong Chen ${ }^{1}$, Richard J. Reynolds ${ }^{2}$, Angelo Gaffo ${ }^{2,3}$, Timothy B. Plante ${ }^{4}$, Jeffrey R. Curtis ${ }^{1,2}$, S. Louis Bridges Jr. ${ }^{2}$, Emily B. Levitan ${ }^{1}$, Ninad S. Chaudhary ${ }^{1}$, George Howard $^{5}$, Monika M. Safford ${ }^{6}$, Paul Muntner ${ }^{1}$ and Marguerite Ryan Irvin ${ }^{1}$

\begin{abstract}
Background: Gout has been associated with a higher risk for coronary heart disease (CHD) and stroke in some prior studies. Few studies have assessed the association of gout with incident heart failure (HF).

Methods: We analyzed data from 5713 black and white men and women $\geq 65.5$ years of age in the populationbased REasons for Geographic And Racial Differences in Stroke (REGARDS) cohort study who had Medicare coverage without a history of HF, CHD, or stroke at baseline between 2003 and 2007. Gout was defined by $\geq 1$ hospitalization or $\geq 2$ outpatient visits with a diagnosis code for gout in Medicare claims prior to each participant's baseline study examination. REGARDS study participants were followed for HF hospitalization, CHD, stroke, and all-cause mortality as separate outcomes through December 31, 2016. Analyses were replicated in a random sample of 839,059 patients $\geq$ 65.5 years of age with Medicare coverage between January 1, 2008, and June 30, 2015, who were followed through December 31, 2017.
\end{abstract}

*Correspondence: Icolantonio@uab.edu

'Department of Epidemiology, University of Alabama at Birmingham, 1720 2nd Ave South, RPHB 527C, Birmingham, AL 35294-0013, USA

Full list of author information is available at the end of the article

C C The Author(s). 2020 Open Access This article is licensed under a Creative Commons Attribution 4.0 International License, which permits use, sharing, adaptation, distribution and reproduction in any medium or format, as long as you give appropriate credit to the original author(s) and the source, provide a link to the Creative Commons licence, and indicate if changes were made. The images or other third party material in this article are included in the article's Creative Commons licence, unless indicated otherwise in a credit line to the material. If material is not included in the article's Creative Commons licence and your intended use is not permitted by statutory regulation or exceeds the permitted use, you will need to obtain permission directly from the copyright holder. To view a copy of this licence, visit http://creativecommons.org/licenses/by/4.0/. The Creative Commons Public Domain Dedication waiver (http://creativecommons.org/publicdomain/zero/1.0/) applies to the data made available in this article, unless otherwise stated in a credit line to the data. 
(Continued from previous page)

Results: Among REGARDS study participants included in the current analysis, the mean age at baseline was 72.6 years, 44.9\% were men, 31.4\% were black, and 3.3\% had gout. Over a median follow-up of 10.0 years, incidence rates per 1000 person-years among participants with and without gout were 13.1 and 4.4 for HF hospitalization, 16.0 and 9.3 for CHD, 9.3 and 8.2 for stroke, and 55.0 and 37.1 for all-cause mortality, respectively. After multivariable adjustment for sociodemographic variables and cardiovascular risk factors, hazard ratios (95\% Cl) comparing participants with versus without gout were $1.97(1.22,3.19)$ for HF hospitalization, $1.21(0.79,1.84)$ for CHD, $0.83(0.48,1.43)$ for stroke, and 1.08 $(0.86,1.35)$ for all-cause mortality. The multivariable-adjusted hazard ratio for HF hospitalization with reduced and preserved left ventricular ejection fraction among participants with versus without gout was 1.77 (95\% Cl 0.83, 3.79) and 2.32 (95\% Cl 1.12,4.79), respectively. The multivariable-adjusted hazard ratio for heart failure hospitalization associated with gout among the 839,059 Medicare beneficiaries was 1.32 (95\% Cl 1.25, 1.39).

Conclusion: Among older adults, gout was associated with an increased risk for incident HF but not for incident CHD, incident stroke, or all-cause mortality.

Keywords: Gout, Heart failure, Cardiovascular disease, Risk factors

\section{Background}

Prior studies suggest that gout, an inflammatory disease caused by the deposit of monosodium urate crystals in joints and tissues [1], is associated with an increased risk for atherosclerotic cardiovascular disease, including coronary heart disease (CHD) and stroke [2-4]. Many risk factors for CHD and stroke, including hypertension, diabetes, cigarette smoking, and obesity, are also associated with an increased risk for heart failure (HF) [5]. If gout is associated with an increased risk for HF, this would support the need for interventions to prevent its occurrence in this population.

The objective of the current study was to determine the risk for incident HF associated with gout in a populationbased cohort of black and white adults enrolled in the REasons for Geographic And Racial Differences in Stroke (REGARDS) study [6]. Additionally, we evaluated the association of gout with incident CHD, incident stroke, and all-cause mortality. We replicated the analysis in a random sample of Medicare beneficiaries to determine whether associations in the REGARDS study were also present in an independent study sample.

\section{Methods}

The REGARDS study enrolled 30,239 black and white participants $\geq 45$ years of age from all 48 contiguous US states and the District of Columbia between January 2003 and October 2007 [6]. Claims of REGARDS study participants in Medicare, a government health insurance program for US adults $\geq 65$ years of age, were obtained from the Centers for Medicare and Medicaid Services Chronic Conditions Warehouse (CMS-CCW) [7]. Gout was not assessed at baseline in the REGARDS study. For this analysis, we included REGARDS study participants $\geq 65.5$ years of age with continuous Medicare fee-forservice inpatient and outpatient coverage for $\geq 182$ days prior to their baseline in-home study visit to identify gout through Medicare claims. After excluding participants with a history of HF, CHD, or stroke as defined in Supplemental Table 1, or without follow-up contacts for outcome identification, a total of 5713 REGARDS study participants were included in the current analysis (Supplemental Figure 1).

\section{Baseline assessment}

REGARDS study participants completed a telephone interview and an in-home visit at baseline. During the in-home visit, trained health professionals conducted a physical examination, an electrocardiogram, and a medication inventory and collected blood and urine samples. Participants were requested to complete the Block 98 food frequency questionnaire (FFQ) and return it after the in-home visit using a pre-paid envelope.

For the current analysis, we used data on participants' age, race, gender, geographic region of residence, income, education, alcohol consumption, smoking status, body mass index (BMI), physical activity, diabetes, chronic kidney disease (CKD), atrial fibrillation, systolic blood pressure, total cholesterol, high-density lipoprotein (HDL) cholesterol, C-reactive protein, and use of antihypertensive medication, diuretics, statin, aspirin, and cyclooxygenase2-selective and non-cyclooxygenase-2-selective nonsteroidal anti-inflammatory drugs (NSAIDs), as defined in Supplemental Table 2. We also used scores for adherence to five dietary patterns (i.e., convenience, plant-based, sweets, southern and alcohol/salads) identified through factor analysis of Block 98 FFQ data [8]. The use of antigout medication, including allopurinol, colchicine, and probenecid, was defined based on the baseline medication inventory. Febuxostat was not approved by the Food and Drugs Administration until 2009 [9]. Gout was defined by $\geq 1$ hospitalization or $\geq 2$ outpatient visits with an International Classification of Diseases, ninth revision diagnosis 
code of 274.xx in Medicare claims at any time prior to each participant's baseline examination $[10,11]$.

\section{Outcomes identification}

REGARDS study participants or proxy respondents were followed through biannual telephone contacts to identify deaths and hospitalizations related with HF, CHD, and stroke events [6, 12]. Medical records for suspected events were retrieved, and hospitalizations for HF and myocardial infarctions (MI) were confirmed by trained clinicians following published guidelines [13-15]. Using hospital records from confirmed HF hospitalizations, the left ventricular ejection fraction (LVEF) was classified as reduced (LVEF $<50 \%$ or qualitative report of abnormal LVEF) or preserved (LVEF $\geq 50 \%$ or qualitative report of normal LVEF) [16]. Hospitalizations for stroke events were confirmed by a panel of neurologists following the World Health Organization definition [17]. Events characterized by symptoms lasting $<24 \mathrm{~h}$ with neuroimaging consistent with acute infarct or hemorrhage were also classified as strokes. When deaths were identified, trained clinicians determined whether a CHD or stroke event was the main underlying cause of death based on interviews with next-of-kin, medical records, death certificates, and autopsy reports $[14,18]$. Data on incident HF hospitalizations, CHD (i.e., MI or CHD death), stroke (fatal or nonfatal), and all-cause mortality were available through December 31, 2016.

\section{Statistical analysis}

We compared characteristics of REGARDS study participants with and without gout using chi-squared tests for categorical variables and $t$ tests for continuous variables. We calculated the crude cumulative incidence by the Kaplan-Meier method and the incidence rate of $\mathrm{HF}$ hospitalization, CHD, stroke, and all-cause mortality among participants with and without gout, separately. Hazard ratios (HR) for HF hospitalization, CHD, stroke, and all-cause mortality, separately, comparing participants with versus without gout were calculated using four Cox regression models. Model 1 included adjustment for age, race, and gender. Model 2 included adjustment for age, race, gender, region of residence, income, and education. Model 3 included adjustment for variables in model 2 and alcohol consumption, current smoking, BMI, physical activity, and dietary patterns. Model 4 included adjustment for variables in model 3 and diabetes, CKD, atrial fibrillation, systolic blood pressure, total and HDL cholesterol, C-reactive protein, and use of antihypertensive medication, diuretics, statin, aspirin, and cyclooxygenase-2-selective and noncyclooxygenase-2-selective NSAIDs. Also, we calculated the crude cumulative incidence, incidence rate, and HR for HF hospitalization with reduced and preserved LVEF, separately, among participants with and without gout.

To test whether HRs associated with gout differed by race or gender, we repeated the analysis using interaction terms between gout and race, and gout and gender, separately. Chained equations were used to obtain 35 multiple imputed datasets in Stata 13 (Stata Corp, College Station, TX) to retain REGARDS study participants with missing data in the regression models (Supplemental Table 3) [19].

\section{Sensitivity analyses}

Few participants without a diagnosis of gout were taking antigout medication $(n=61)$. Antigout medications were not used to define gout in the main analysis as these may have other indications (e.g., inflammatory bowel disease). In a sensitivity analysis, we compared the risk for HF hospitalization, CHD, stroke, and all-cause mortality among participants with gout or taking antigout medication versus those without gout who were not taking antigout medication. Some participants had evidence of HF, CHD, or cerebrovascular disease based on Medicare claims as defined in Supplemental Table 4 before their baseline in-home study visit $(n=1096)$. We analyzed the risk for HF hospitalization, CHD, stroke, and all-cause mortality associated with gout after excluding these participants in a sensitivity analysis.

\section{Medicare cohort}

We obtained claims data for a $5 \%$ random sample of Medicare beneficiaries from the CMS-CCW. For each beneficiary, we generated a random index date between January 1, 2008, and June 30, 2015. Beneficiaries $\geq 65.5$ years of age with Medicare fee-for-service inpatient, outpatient, and pharmacy coverage for the preceding $\geq 182$ days and without a history of HF, CHD, or cerebrovascular disease (as defined in Supplemental Table 4) on their index date were included in the analysis $(n=839$, 059, Supplemental Figure 2). We excluded Medicare beneficiaries before January 1, 2008, to allow for at least 182 days of inpatient, outpatient, and pharmacy coverage to define beneficiary characteristics as the Medicare pharmacy benefits program did not start until 2006 but its usage did not increase until 2007 [20]. Definitions of gout and beneficiary characteristics are provided in Supplemental Table 5.

Medicare beneficiaries were followed for HF, MI, and stroke hospitalizations and all-cause mortality as defined in Supplemental Table 6 from their index date through December 31, 2017, or loss of fee-for-service inpatient or outpatient coverage. We calculated the crude cumulative incidence and incidence rate of HF, MI, and stroke hospitalizations and all-cause mortality among beneficiaries with and without gout. We used three Cox 
Table 1 Baseline characteristics of REGARDS study participants included in the current analysis

\begin{tabular}{|c|c|c|c|}
\hline Baseline characteristics & Participants without gout $(n=5526)$ & Participants with gout $(n=187)$ & $p$ value \\
\hline Age, years, mean (SD) & $72.5(5.6)$ & $73.8(6.1)$ & 0.003 \\
\hline Black, $n(\%)$ & $1711(31.0)$ & $83(44.4)$ & $<0.001$ \\
\hline Men, $n(\%)$ & $2440(44.2)$ & $123(65.8)$ & $<0.001$ \\
\hline \multicolumn{4}{|l|}{ Region of residence, $n(\%)^{*}$} \\
\hline Stroke belt & $1995(36.1)$ & $61(32.6)$ & \\
\hline Stroke buckle & $1258(22.8)$ & $50(26.7)$ & 0.39 \\
\hline Other US regions & $2273(41.1)$ & $76(40.6)$ & \\
\hline$<\$ 25,000$ annual income, $n(\%)$ & $1790(34.4)$ & $57(32.0)$ & 0.51 \\
\hline Less than high school education, $n$ (\%) & $727(13.2)$ & $38(20.3)$ & 0.005 \\
\hline \multicolumn{4}{|l|}{ Alcohol consumption, $n(\%)$} \\
\hline None & $3527(65.1)$ & $117(63.9)$ & \\
\hline Moderate & $1669(30.8)$ & $59(32.2)$ & 0.90 \\
\hline Heavy & $225(4.2)$ & $7(3.8)$ & \\
\hline Current smoking, $n(\%)$ & $485(8.8)$ & $12(6.5)$ & 0.26 \\
\hline \multicolumn{4}{|l|}{ Body mass index, $n(\%)$} \\
\hline$<25 \mathrm{~kg} / \mathrm{m}^{2}$ & $1749(31.8)$ & $27(14.6)$ & \\
\hline 25 to $<30 \mathrm{~kg} / \mathrm{m}^{2}$ & $2182(39.7)$ & $67(36.2)$ & $<0.001$ \\
\hline$\geq 30 \mathrm{~kg} / \mathrm{m}^{2}$ & $1572(28.6)$ & $91(49.2)$ & \\
\hline Low physical activity, $n(\%)^{\dagger}$ & $1794(33.1)$ & $74(40.7)$ & 0.03 \\
\hline \multicolumn{4}{|l|}{ Dietary patterns } \\
\hline \multicolumn{4}{|l|}{ Convenience } \\
\hline 0 to $<25$ percentile (least adherent) & $1080(25.2)$ & $25(19.4)$ & \\
\hline 25 to $<50$ percentile & $1074(25.0)$ & $31(24.0)$ & 0.19 \\
\hline 50 to $<75$ percentile & $1074(25.0)$ & $31(24.0)$ & \\
\hline 75 to 100 percentile (most adherent) & $1063(24.8)$ & $42(32.6)$ & \\
\hline \multicolumn{4}{|l|}{ Plant-based } \\
\hline 0 to $<25$ percentile (least adherent) & $1070(24.9)$ & $35(27.1)$ & \\
\hline 25 to $<50$ percentile & $1066(24.8)$ & $39(30.2)$ & 0.22 \\
\hline 50 to $<75$ percentile & $1073(25.0)$ & $32(24.8)$ & \\
\hline 75 to 100 percentile (most adherent) & $1082(25.2)$ & $23(17.8)$ & \\
\hline \multicolumn{4}{|l|}{ Sweets } \\
\hline 0 to $<25$ percentile (least adherent) & $1062(24.7)$ & $43(33.3)$ & \\
\hline 25 to $<50$ percentile & $1080(25.2)$ & $25(19.4)$ & 0.13 \\
\hline 50 to $<75$ percentile & $1076(25.1)$ & $29(22.5)$ & \\
\hline 75 to 100 percentile (most adherent) & $1073(25.0)$ & $32(24.8)$ & \\
\hline \multicolumn{4}{|l|}{ Southern } \\
\hline 0 to $<25$ percentile (least adherent) & $1088(25.4)$ & $17(13.2)$ & \\
\hline 25 to $<50$ percentile & $1082(25.2)$ & $23(17.8)$ & $<0.001$ \\
\hline 50 to $<75$ percentile & $1068(24.9)$ & $37(28.7)$ & \\
\hline 75 to 100 percentile (most adherent) & $1053(24.5)$ & $52(40.3)$ & \\
\hline \multicolumn{4}{|l|}{ Alcohol and salads } \\
\hline 0 to $<25$ percentile (least adherent) & $1072(25.0)$ & $33(25.6)$ & \\
\hline 25 to $<50$ percentile & $1073(25.0)$ & $32(24.8)$ & 0.79 \\
\hline 50 to $<75$ percentile & $1077(25.1)$ & $28(21.7)$ & \\
\hline
\end{tabular}


Table 1 Baseline characteristics of REGARDS study participants included in the current analysis (Continued)

\begin{tabular}{|c|c|c|c|}
\hline Baseline characteristics & Participants without gout $(n=5526)$ & Participants with gout $(n=187)$ & $p$ value \\
\hline 75 to 100 percentile (most adherent) & $1069(24.9)$ & $36(27.9)$ & \\
\hline Diabetes, $n(\%)$ & $903(16.9)$ & $52(29.4)$ & $<0.001$ \\
\hline Chronic kidney disease, $n$ (\%) & $1266(23.1)$ & $85(45.9)$ & $<0.001$ \\
\hline Atrial fibrillation, $n(\%)$ & $384(7.1)$ & $15(8.3)$ & 0.55 \\
\hline SBP, mm Hg, mean (SD) & $129.5(16.4)$ & $132.6(15.4)$ & 0.01 \\
\hline Total cholesterol, mg/dL, mean (SD) & $193.2(38.2)$ & $182.5(39.5)$ & $<0.001$ \\
\hline HDL cholesterol, mg/dL, mean (SD) & $53.6(16.6)$ & $46.7(17.2)$ & $<0.001$ \\
\hline C-reactive protein $>3 \mathrm{mg} / \mathrm{dL}, n(\%)$ & $1862(35.7)$ & $94(54.7)$ & $<0.001$ \\
\hline \multicolumn{4}{|l|}{ Medication use, $n(\%)$} \\
\hline Antihypertensive medication & $2764(50.7)$ & $132(70.6)$ & $<0.001$ \\
\hline Diuretics & $1480(26.8)$ & $57(30.5)$ & 0.26 \\
\hline Statin & $1590(28.8)$ & $55(29.4)$ & 0.85 \\
\hline Aspirin & $2476(44.8)$ & $82(43.9)$ & 0.79 \\
\hline COX-2-selective NSAIDs & $423(7.7)$ & $22(11.8)$ & 0.04 \\
\hline Non-COX-2-selective NSAIDs & $828(15.0)$ & $30(16.0)$ & 0.69 \\
\hline \multicolumn{4}{|l|}{ Antigout medications $^{\ddagger}$} \\
\hline Allopurinol & $46(0.8)$ & 63 (33.7) & $<0.001$ \\
\hline Colchicine & $17(0.3)$ & $15(8.0)$ & $<0.001$ \\
\hline Probenecid & $2(0.0)$ & $3(1.6)$ & $<0.001$ \\
\hline
\end{tabular}

Definitions for baseline characteristics included in the analysis are provided in Supplemental Table 2

COX cyclooxygenase, HDL high-density lipoprotein, NSAID nonsteroidal anti-inflammatory drugs, REGARDS REasons for Geographic And Racial Differences in Stroke, SBP systolic blood pressure, SD standard deviation, US United States

*Stroke buckle includes coastal North Carolina, South Carolina, and Georgia. Stroke belt includes the remaining parts of North Carolina, South Carolina, and

Georgia, and Tennessee, Mississippi, Alabama, Louisiana, and Arkansas. Other US regions include the remaining 40 contiguous US states and the District of Columbia

${ }^{\dagger}$ Low physical activity is defined by self-reporting not engaging in any weekly activity intense enough to work up a sweat

${ }^{\ddagger}$ The use of febuxostat was not analyzed at baseline in the REGARDS study as this medication was not approved until 2009 [9]

regression models to calculate HRs for $\mathrm{HF}, \mathrm{MI}$, and stroke hospitalizations and all-cause mortality comparing beneficiaries with versus without gout. Model 1 included adjustment for age, race/ethnicity, and gender. Model 2 included adjustment for age, race/ethnicity, gender, region of residence, and Medicare-Medicaid eligible/low-income subsidy. Model 3 included adjustment for variables in model 2 and diabetes, CKD, atrial fibrillation, hypertension, and use of diuretics, statin (and statin intensity), and cyclooxygenase-2-selective and noncyclooxygenase-2-selective NSAIDs. Data for some variables adjusted for in the analysis of the REGARDS study sample, including alcohol consumption, diet, smoking status, BMI, physical activity, blood pressure, serum cholesterol, and over-the-counter medications (e.g., aspirin), are not available in Medicare claims. We used a $Q$ test for heterogeneity to compare fully adjusted HRs in the Medicare cohort versus those in the REGARDS study. We tested for interaction between gout and race/ ethnicity, and gout and gender, separately, in the Medicare cohort as described for the REGARDS study.

\section{Results}

Overall, 187 (3.3\%) of 5713 REGARDS study participants included in the current analysis had gout. Compared to REGARDS study participants without gout, those with gout were older, and more likely to be black or men, have less than high school education, higher BMI or low physical activity, and have diet consistent with the southern dietary pattern, diabetes, CKD, or higher levels of systolic blood pressure or C-reactive protein (Table 1). Participants with gout had lower total and HDL cholesterol versus those without gout. A higher proportion of participants with versus without gout were taking antihypertensive medication and cyclooxygenase-2-selective NSAIDs.

REGARDS study participants with gout had higher cumulative incidence and incidence rate of $\mathrm{HF}$ hospitalization, CHD, and all-cause mortality, and similar cumulative incidence and incidence rate of stroke, versus their counterparts without gout (Fig. 1 and Table 2). After multivariable adjustment, gout was associated with a higher risk for HF hospitalization (HR 1.97, 

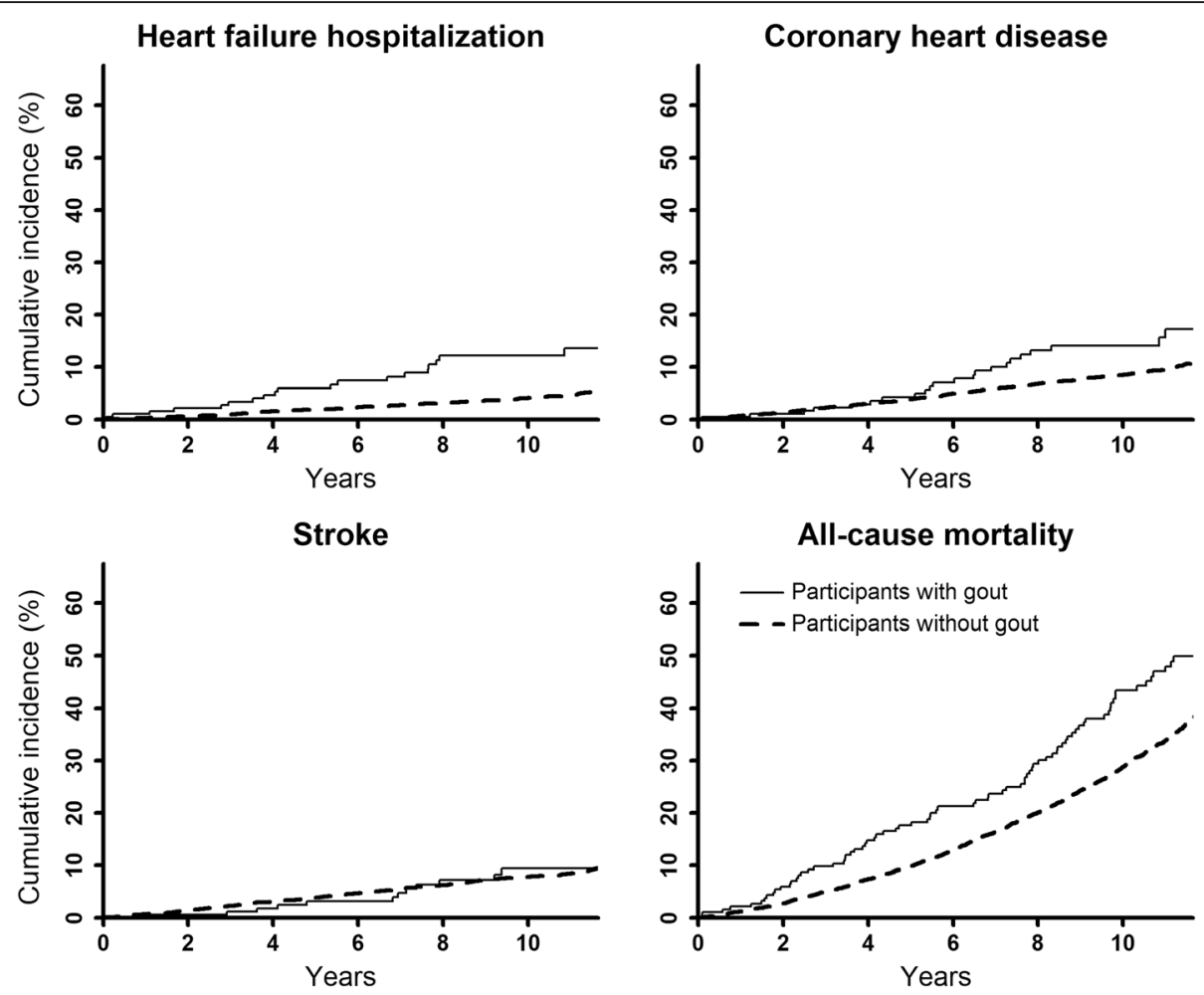

Fig. 1 Cumulative incidence of HF hospitalization, CHD, stroke, and all-cause mortality among REGARDS study participants. CHD, coronary heart disease; HF, heart failure; REGARDS, REasons for Geographic And Racial Differences in Stroke. Cumulative incidence curves are unadjusted

95\% confidence interval [95\% CI] 1.22, 3.19). There were no statistically significant differences in the risk for CHD, stroke, and all-cause mortality among participants with versus without gout after multivariable adjustment. Gout was associated with an increased risk for HF hospitalization with both reduced and preserved LVEF (Supplemental Figure 3 and Table 3).

The risk for HF hospitalization associated with gout was not statistically significantly different between black and white participants (Supplemental Table 7). Also, there was no evidence of an association of gout with CHD or stroke among black or white participants. Gout was associated with an increased risk for all-cause mortality among black participants, but not among white participants (multivariable-adjusted HRs [95\% CI] 1.46 $[1.05,2.02]$ and $0.85[0.61,1.17]$, respectively, $p$ value for the difference in HRs 0.02). When stratified by gender, gout was associated with an increased risk for HF hospitalization among both men and women, but there was no evidence of an association with CHD, stroke, or all-cause mortality in either group (Supplemental Table 8).

\section{Sensitivity analyses}

REGARDS study participants with gout or taking antigout medication $(n=248 ; 4.3 \%)$ had a higher incidence rate of HF hospitalization, CHD, stroke, and all-cause mortality compared with their counterparts without gout who were not taking antigout medication (Supplemental Table 9). After multivariable adjustment, participants with gout or taking antigout medication had a higher risk for HF hospitalization versus those without gout who were not taking antigout medication, but there were no statistically significant differences in the risk for CHD, stroke, or all-cause mortality. After excluding 1096 REGARDS study participants with evidence of HF, CHD, or cerebrovascular disease based on Medicare claims, the fully adjusted $\mathrm{HRs}(95 \% \mathrm{CI})$ for $\mathrm{HF}$ hospitalization, CHD, stroke, and all-cause mortality associated with gout were $1.67(0.90,3.12), 1.01(0.58$, $1.76), 0.76(0.38,1.49)$, and $0.96(0.72,1.28)$, respectively (Supplemental Table 10).

\section{Medicare cohort}

Medicare beneficiaries with gout $(n=29,753$ [3.6\%] of $839,059)$ were older and more likely to be non-Hispanic black or men; to have diabetes, CKD, atrial fibrillation, or hypertension; and to be taking a diuretic, statin, or non-cyclooxygenase-2-selective NSAID versus those without gout (Supplemental Table 11). Compared to Medicare beneficiaries without gout, those with gout had a higher cumulative incidence and incidence rate of 
Table 2 Risk for HF hospitalization, coronary heart disease, stroke, and all-cause mortality among REGARDS study participants

\begin{tabular}{|c|c|c|c|}
\hline & Participants without gout $(n=5526)$ & Participants with gout $(n=187)$ & $p$ value \\
\hline \multicolumn{4}{|l|}{ HF hospitalization } \\
\hline Events/person-years & $223 / 50,163$ & 20/1522 & \\
\hline Incidence rate $(95 \% \mathrm{Cl})^{*}$ & $4.4(3.9,5.0)$ & $13.1(7.4,18.9)$ & \\
\hline \multicolumn{4}{|l|}{ Hazard ratio $(95 \% \mathrm{Cl})$} \\
\hline Model 1 & 1 (reference) & $2.59(1.63,4.11)$ & $<0.001$ \\
\hline Model 2 & 1 (reference) & $2.59(1.63,4.11)$ & $<0.001$ \\
\hline Model 3 & 1 (reference) & $2.27(1.41,3.66)$ & 0.001 \\
\hline Model 4 & 1 (reference) & $1.97(1.22,3.19)$ & 0.006 \\
\hline \multicolumn{4}{|l|}{ Coronary heart disease } \\
\hline Events/person-years & $453 / 48,904$ & $24 / 1504$ & \\
\hline Incidence rate $(95 \% \mathrm{Cl})^{*}$ & $9.3(8.4,10.1)$ & $16.0(9.6,22.3)$ & \\
\hline \multicolumn{4}{|l|}{ Hazard ratio $(95 \% \mathrm{Cl})$} \\
\hline Model 1 & 1 (reference) & $1.47(0.97,2.22)$ & 0.07 \\
\hline Model 2 & 1 (reference) & $1.46(0.97,2.21)$ & 0.07 \\
\hline Model 3 & 1 (reference) & $1.38(0.91,2.09)$ & 0.14 \\
\hline Model 4 & 1 (reference) & $1.21(0.79,1.84)$ & 0.39 \\
\hline \multicolumn{4}{|l|}{ Stroke } \\
\hline Events/person-years & $398 / 48,702$ & $14 / 1512$ & \\
\hline Incidence rate $(95 \% \mathrm{Cl})^{*}$ & $8.2(7.4,9.0)$ & $9.3(4.4,14.1)$ & \\
\hline \multicolumn{4}{|l|}{ Hazard ratio $(95 \% \mathrm{Cl})$} \\
\hline Model 1 & 1 (reference) & $1.03(0.60,1.75)$ & 0.93 \\
\hline Model 2 & 1 (reference) & $1.01(0.59,1.73)$ & 0.97 \\
\hline Model 3 & 1 (reference) & $0.95(0.56,1.64)$ & 0.87 \\
\hline Model 4 & 1 (reference) & $0.83(0.48,1.43)$ & 0.51 \\
\hline \multicolumn{4}{|l|}{ All-cause mortality } \\
\hline Events/person-years & $1858 / 50,142$ & $85 / 1545$ & \\
\hline Incidence rate $(95 \% \mathrm{Cl})^{*}$ & $37.1(35.4,38.7)$ & $55.0(43.3,66.7)$ & \\
\hline \multicolumn{4}{|l|}{ Hazard ratio $(95 \% \mathrm{Cl})$} \\
\hline Model 1 & 1 (reference) & $1.24(1.00,1.54)$ & 0.05 \\
\hline Model 2 & 1 (reference) & $1.22(0.98,1.52)$ & 0.07 \\
\hline Model 3 & 1 (reference) & $1.19(0.95,1.48)$ & 0.13 \\
\hline Model 4 & 1 (reference) & $1.08(0.86,1.35)$ & 0.51 \\
\hline
\end{tabular}

Model 1 adjusts for age, race, and gender

Model 2 adjusts for age, race, gender, region of residence, income, and education

Model 3 adjusts for variables in model 2 plus alcohol consumption, current smoking, body mass index, physical activity, and dietary patterns

Model 4 adjusts for variables in model 3 plus diabetes, chronic kidney disease, atrial fibrillation, systolic blood pressure, total cholesterol, high-density lipoprotein

cholesterol, C-reactive protein, and use of antihypertensive medication, diuretics, statin, aspirin, and cyclooxygenase-2-selective and non-cyclooxygenase-2-

selective nonsteroidal anti-inflammatory drugs

The median (maximum) follow-up for all-cause mortality was 10.0 (13.9) years

Cl confidence interval, HF heart failure, REGARDS REasons for Geographic And Racial Differences in Stroke

*Per 1000 person-years

HF, MI, and stroke hospitalizations and all-cause mortality (Fig. 2 and Table 4). After multivariable adjustment, Medicare beneficiaries with gout had a higher risk for HF hospitalization and a lower risk for all-cause mortality compared to those without gout. The multivariableadjusted hazard ratio for MI hospitalization and stroke associated with gout was 1.06 (95\% CI 1.00, 1.11) and
1.06 (95\% CI 1.00, 1.12), respectively. Fully adjusted HRs in the Medicare cohort were not statistically significantly different versus those among REGARDS study participants (Table 5).

HRs for HF, MI, and stroke hospitalizations and allcause mortality associated with gout were not statistically significantly different across subgroups defined by 
Table 3 Risk for heart failure hospitalization with reduced and preserved LVEF among REGARDS study participants

\begin{tabular}{|c|c|c|c|}
\hline & Participants without gout $(n=5526)$ & Participants with gout $(n=187)$ & $p$ value \\
\hline \multicolumn{4}{|c|}{ HF hospitalization with reduced LVEF } \\
\hline Events/person-years & $92 / 50,163$ & $8 / 1522$ & \\
\hline Incidence rate $(95 \% \mathrm{Cl})^{*}$ & $1.8(1.5,2.2)$ & $5.3(1.6,8.9)$ & \\
\hline \multicolumn{4}{|l|}{ Hazard ratio $(95 \% \mathrm{Cl})$} \\
\hline Model 1 & 1 (reference) & $2.41(1.16,5.01)$ & 0.02 \\
\hline Model 2 & 1 (reference) & $2.49(1.20,5.17)$ & 0.01 \\
\hline Model 3 & 1 (reference) & $2.17(1.03,4.59)$ & 0.04 \\
\hline Model 4 & 1 (reference) & $1.77(0.83,3.79)$ & 0.14 \\
\hline \multicolumn{4}{|c|}{ HF hospitalization with preserved LVEF } \\
\hline Events/person-years & $99 / 50,163$ & $9 / 1522$ & \\
\hline Incidence rate $(95 \% \mathrm{Cl})^{*}$ & $2.0(1.6,2.4)$ & $5.9(2.1,9.8)$ & \\
\hline \multicolumn{4}{|l|}{ Hazard ratio $(95 \% \mathrm{Cl})$} \\
\hline Model 1 & 1 (reference) & $2.93(1.46,5.85)$ & $<0.001$ \\
\hline Model 2 & 1 (reference) & $2.85(1.42,5.70)$ & $<0.001$ \\
\hline Model 3 & 1 (reference) & $2.56(1.25,5.22)$ & 0.01 \\
\hline Model 4 & 1 (reference) & $2.32(1.12,4.79)$ & 0.02 \\
\hline
\end{tabular}

Model 1 adjusts for age, race, and gender

Model 2 adjusts for age, race, gender, region of residence, income, and education

Model 3 adjusts for variables in model 2 plus alcohol consumption, current smoking, body mass index, physical activity, and dietary patterns

Model 4 adjusts for variables in model 3 plus diabetes, chronic kidney disease, atrial fibrillation, systolic blood pressure, total cholesterol, high-density lipoprotein

cholesterol, C-reactive protein, and use of antihypertensive medication, diuretics, statin, aspirin, and cyclooxygenase-2-selective and non-cyclooxygenase-2-

selective nonsteroidal anti-inflammatory drugs

The LVEF could not be determined for 35 incident heart failure hospitalizations

$\mathrm{Cl}$ confidence interval, HF heart failure, LVEF left ventricular ejection fraction, REGARDS REasons for Geographic And Racial Differences in Stroke

*Per 1000 person-years

race/ethnicity (Supplemental Table 12). After multivariable adjustment, gout was associated with a higher risk for $\mathrm{HF}$ and stroke hospitalization and lower all-cause mortality among men, and with a higher risk for HF and MI hospitalization among women (Supplemental Table 13).

\section{Discussion}

In the current analysis, gout was associated with an increased risk for incident HF hospitalization among REGARDS study participants without a history of HF, $\mathrm{CHD}$, or stroke. This association was present among blacks and whites and among men and women. In contrast, gout was not associated with incident CHD, stroke, or all-cause mortality after multivariable adjustment. The higher risk for incident HF associated with gout was also present in a large random sample of Medicare beneficiaries. These findings suggest that gout may be a risk factor for incident HF.

In the Framingham Offspring Study, a cohort composed exclusively of white adults, the HR for incident HF comparing participants with versus without gout was 1.74 (95\% CI 1.03, 2.93) [21]. However, this study did not exclude individuals with a history of CHD or stroke at baseline and did not adjust for these conditions as part of the analysis. In the current analysis, gout was associated with a higher risk for incident HF in a cohort of individuals without a history of CHD or stroke and after adjustment for relevant risk factors for HF, including hypertension [22, 23], diabetes [23], cigarette smoking [23], obesity [24], high adherence to a southern dietary pattern [15], and use of NSAID [25]. These results support that the association of gout with incident HF is independent of a prior history of atherosclerosis disease or other well-known risk factors.

It has been previously shown that there is an attenuation in the association between many risk factors and cardiovascular events at an older age [26]. Prior studies suggest that gout is associated with a higher risk for $\mathrm{CHD}$ and stroke $[2,3]$. However, this association may also be attenuated at an older age [2, 27]. In a population-based cohort of 704,503 adults with healthcare coverage through the National Health Insurance in Taiwan, multivariable-adjusted HRs for MI associated with gout were 1.59 (95\% CI 1.12, 2.24) among those $20-44$ years of age and 1.11 (95\% CI $0.94,1.32)$ among those $\geq 70$ years of age [28]. In the current analysis of a random sample of Medicare beneficiaries $\geq 65.5$ years of age, multivariable-adjusted HRs for $\mathrm{MI}$ and stroke were 1.06 (95\% CI 1.00, 1.11) and 1.06 (95\% CI 1.00, 1.12), 

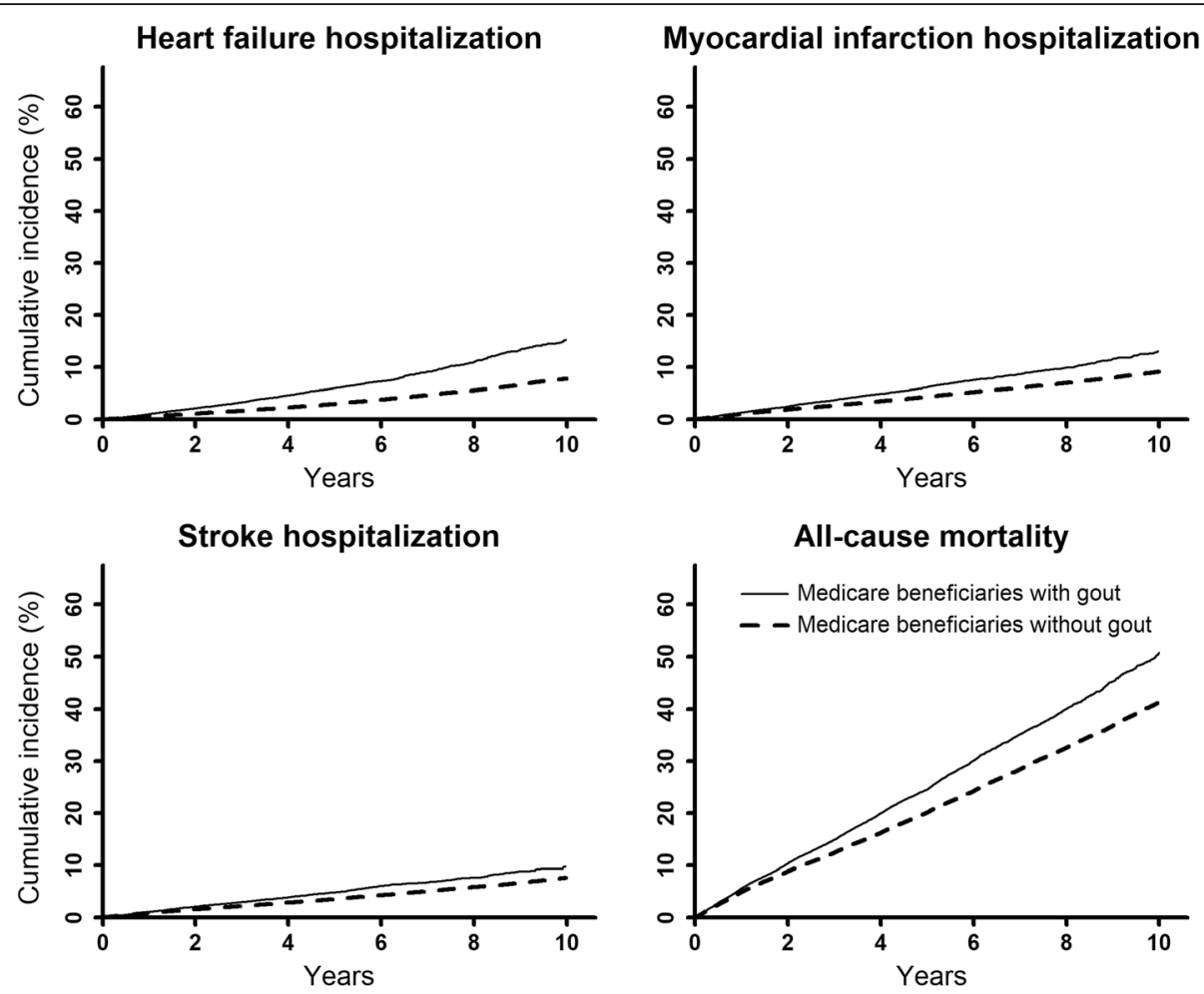

Fig. 2 Cumulative incidence of HF, myocardial infarction, and stroke hospitalization and all-cause mortality among Medicare beneficiaries. HF, heart failure. Cumulative incidence curves are unadjusted

respectively. Therefore, results from the current analysis do not exclude that gout may be associated with a small increase in the risk for CHD or stroke among older adults. Rather, results from the current study support that these associations may be attenuated at an older age. Given that the association of gout with incident CHD and stroke appears to be stronger among young versus older adults [2, 27, 28], it is possible that the association of gout with incident HF may also be stronger at a younger age.

Results from the current study suggest that a prior history of atherosclerotic cardiovascular disease or the development of atherosclerotic cardiovascular disease during follow-up do not explain the increased risk for HF associated with gout among older adults. However, the mechanisms behind this association remain unknown. In the current analysis, gout was associated with a higher risk for incident HF with preserved and reduced LVEF. HF with preserved and reduced LVEF has different underlying pathophysiology [29]. Patients with HF who have reduced LVEF are more likely to show upregulation of pathways related to cellular growth and metabolism, while those who have preserved LVEF are more likely to show upregulation of pathways related to inflammation and extracellular matrix reorganization [30]. Therefore, it is possible that gout may contribute to the development of HF through different pathways.
Understanding the biological mechanisms involved in the development of HF in older adults with gout may contribute to identify therapeutic targets to prevent or treat HF in this population.

Inflammation, insulin resistance, and high serum urate levels may, in part, explain the increased risk for HF in adults with gout [31-36]. Interleukin-1 is a key inflammatory marker involved in the development of gout flares, as it was demonstrated in recent clinical trials with interleukin-1 blockade [37-39]. Interleukin-1 overexpression has been associated with the development of HF with preserved LVEF in animal models [31, 32]. Also, interleukin-1 blockade showed a dose-dependent reduction in the risk for HF hospitalization among adults with a previous $\mathrm{MI}$ and high C-reactive protein levels in the Canakinumab Anti-Inflammatory Thrombosis Outcomes Study (CANTOS) clinical trial [40]. Insulin resistance is common in adults with gout $[41,42]$. Prior studies have shown that insulin resistance is associated with an increased risk for incident HF independently of diabetes and obesity [33, 34]. Furthermore, insulin resistance has been associated with both preserved and reduced LVEF HF [43]. Finally, hyperuricemia was associated with an increased risk for incident HF in the Cardiovascular Health Study (multivariableadjusted HF 1.30, 95\% CI 1.05, 1.60) [35]. Future studies should determine whether interleukin-1 blockade, 
Table 4 Risk for heart failure, myocardial infarction, and stroke hospitalization and all-cause mortality among Medicare beneficiaries

\begin{tabular}{|c|c|c|c|}
\hline & Medicare beneficiaries without gout $(n=809,306)$ & Medicare beneficiaries with gout $(n=29,753)$ & $p$ value \\
\hline \multicolumn{4}{|l|}{ Heart failure hospitalization } \\
\hline Events/person-years & $19,407 / 3,064,851$ & $1477 / 115,128$ & - \\
\hline Incidence rate $(95 \% \mathrm{Cl})^{*}$ & $6.3(6.2,6.4)$ & $12.8(12.2,13.5)$ & - \\
\hline \multicolumn{4}{|l|}{ Hazard ratio $(95 \% \mathrm{Cl})$} \\
\hline Model 1 & 1 (reference) & $1.72(1.63,1.82)$ & $<0.001$ \\
\hline Model 2 & 1 (reference) & $1.74(1.65,1.83)$ & $<0.001$ \\
\hline Model 3 & 1 (reference) & $1.32(1.25,1.39)$ & $<0.001$ \\
\hline \multicolumn{4}{|c|}{ Myocardial infarction hospitalization } \\
\hline Events/person-years & $27,553 / 3,039,727$ & $1479 / 114,759$ & - \\
\hline Incidence rate $(95 \% \mathrm{Cl})^{*}$ & $9.1(9.0,9.2)$ & $12.9(12.2,13.5)$ & - \\
\hline \multicolumn{4}{|l|}{ Hazard ratio $(95 \% \mathrm{Cl})$} \\
\hline Model 1 & 1 (reference) & $1.19(1.13,1.26)$ & $<0.001$ \\
\hline Model 2 & 1 (reference) & $1.21(1.15,1.27)$ & $<0.001$ \\
\hline Model 3 & 1 (reference) & $1.06(1.00,1.11)$ & 0.05 \\
\hline \multicolumn{4}{|l|}{ Stroke hospitalization } \\
\hline Events/person-years & $22,657 / 3,050,349$ & $1152 / 115,356$ & - \\
\hline Incidence rate $(95 \% \mathrm{Cl})^{*}$ & $7.4(7.3,7.5)$ & $10.0(9.4,10.6)$ & - \\
\hline \multicolumn{4}{|l|}{ Hazard ratio (95\% Cl) } \\
\hline Model 1 & 1 (reference) & $1.14(1.07,1.21)$ & $<0.001$ \\
\hline Model 2 & 1 (reference) & $1.14(1.08,1.22)$ & $<0.001$ \\
\hline Model 3 & 1 (reference) & $1.06(1.00,1.12)$ & 0.07 \\
\hline \multicolumn{4}{|l|}{ All-cause mortality } \\
\hline Events/person-years & $145,623 / 3,101,396$ & 7013/117,902 & - \\
\hline Incidence rate $(95 \% \mathrm{Cl})^{*}$ & $47.0(46.7,47.2)$ & $59.5(58.1,60.9)$ & - \\
\hline \multicolumn{4}{|l|}{ Hazard ratio (95\% Cl) } \\
\hline Model 1 & 1 (reference) & $1.02(1.00,1.05)$ & 0.08 \\
\hline Model 2 & 1 (reference) & $1.04(1.02,1.07)$ & 0.001 \\
\hline Model 3 & 1 (reference) & $0.95(0.93,0.98)$ & $<0.001$ \\
\hline
\end{tabular}

Model 1 includes adjustment for age, gender, and race/ethnicity

Model 2 includes adjustment for age, gender, race/ethnicity, region of residence, and Medicare-Medicaid eligible/low-income subsidy

Model 3 includes adjustment for variables in model 2 and diabetes, chronic kidney disease, atrial fibrillation, hypertension, and use of diuretics, statin (and statin intensity), and cyclooxygenase-2-selective and non-cyclooxygenase-2-selective nonsteroidal anti-inflammatory drugs

The median (maximum) follow-up for all-cause mortality was 3.1 (10.0) years

$\mathrm{Cl}$ confidence interval

*Per 1000 person-years

pharmacologic insulin sensitization, or uric acidlowering therapy is effective to reduce the risk for $\mathrm{HF}$ among adults with gout [44].

Gout was associated with a higher risk for all-cause mortality among middle-aged male participants without a history of CHD in the Health Professionals Follow-up Study (mean age 54 years) [45] and in the Multiple Risk Factor Intervention Trial (mean age 52 years) [46]. In the current analysis of REGARDS study participants $\geq$ 65.5 years of age without a history of CHD or stroke, gout was associated with a higher all-cause mortality among black but not among white participants. In the random sample of Medicare beneficiaries $\geq 65.5$ years of age, gout was associated with a lower risk for all-cause mortality after multivariable adjustment, without evidence of effect modification by race or gender.

The current study has several strengths, including the use of data from the REGARDS study, a cohort with a rigorous cardiovascular event adjudication process. REGARDS study participants $\geq 65$ years of age with Medicare fee-for-service coverage are representative of the general US population $\geq 65$ years of age with the same healthcare insurance [7]. Also, we replicated the analysis in a random sample of Medicare beneficiaries. Despite these strengths, the current study has known and potential limitations. Although the use of claims to identify gout may result in some misclassification [47], diagnosis codes for gout have been shown to have a high sensitivity and 
Table 5 Fully adjusted hazard ratios for outcome events in the REGARDS study and Medicare cohort

\begin{tabular}{|c|c|c|c|}
\hline & \multicolumn{2}{|c|}{ Hazard ratio ( $95 \%$ confidence interval)* } & \multirow{2}{*}{$\begin{array}{l}Q \text { test } \\
p \text { value }\end{array}$} \\
\hline & REGARDS study $(n=5713)$ & Medicare cohort $(n=839,059)$ & \\
\hline Heart failure & $1.97(1.22,3.19)$ & $1.32(1.25,1.39)$ & 0.10 \\
\hline Coronary heart disease/myocardial infarction & $1.21(0.79,1.84)$ & $1.06(1.00,1.11)$ & 0.55 \\
\hline Stroke & $0.83(0.48,1.43)$ & $1.06(1.00,1.12)$ & 0.39 \\
\hline All-cause mortality & $1.08(0.86,1.35)$ & $0.95(0.93,0.98)$ & 0.27 \\
\hline
\end{tabular}

Hazard ratios in REGARDS include adjustment for age, race, gender, region of residence, income, education, alcohol consumption, current smoking, body mass index, physical activity, dietary patterns, diabetes, chronic kidney disease, atrial fibrillation, systolic blood pressure, total cholesterol, high-density lipoprotein cholesterol, C-reactive protein, and use of antihypertensive medication, diuretics, statin, aspirin, and cyclooxygenase-2-selective and non-cyclooxygenase-2selective nonsteroidal anti-inflammatory drugs

Hazard ratios in Medicare include adjustment for age, gender, race/ethnicity, region of residence, Medicare-Medicaid eligible/low-income subsidy, diabetes, chronic kidney disease, atrial fibrillation, hypertension, and use of diuretics, statin (and statin intensity), and cyclooxygenase-2-selective and non-cyclooxygenase-2selective nonsteroidal anti-inflammatory drugs

*Comparing older adults with versus without gout

specificity to identify gout-related visits in prior analyses $[10,48]$. Also, results were consistent with the main analysis when we compared REGARDS study participants with gout or taking antigout medication versus their counterparts without gout who were not taking antigout medication. Many REGARDS study participants did not return complete Block 98 FFQ data [8], which required the use of multiple imputation to include dietary information in regression models. Levels of interleukin-1, insulin, and serum urate were not available for the current study.

\section{Conclusions}

Results from the current study suggest that gout is a risk factor for incident HF among older adults. The higher risk for incident HF associated with gout was consistent for whites and blacks and men and women and was present in the REGARDS study cohort and in a random selection of Medicare beneficiaries. Interventions to reduce the excess risk for incident HF among older adults with gout are warranted.

\section{Supplementary information}

Supplementary information accompanies this paper at https://doi.org/10. 1186/s13075-020-02175-2.

\section{Additional file 1}

\section{Abbreviations}

BMI: Body mass index; CHD: Coronary heart disease; Cl: Confidence interval; CKD: Chronic kidney disease; CMS-CCW: Centers for Medicare and Medicaid Services Chronic Conditions Warehouse; FFQ: Food frequency questionnaire; HF: Heart failure; HR: Hazard ratio; LVEF: Left ventricular ejection fraction; MI: Myocardial infarction; NSAID: Nonsteroidal anti-inflammatory drug; REGARDS: REasons for Geographic And Racial Differences in Stroke

\section{Acknowledgements}

The content is solely the responsibility of the authors and does not necessarily represent the official views of the National Institute of Neurological Disorders and Stroke, the National Institute on Aging or the National Heart, Lung, and Blood Institute. The authors thank the other investigators, the staff, and the participants of the REGARDS study for their valuable contributions. A full list of participating REGARDS investigators and institutions and further information about the study can be found at http://www.regardsstudy.org.

\section{Authors' contributions}

LDC had full access to all of the data in the study and takes responsibility for the integrity of the data and the accuracy of the data analysis. Study concept and design were contributed by LDC, KGS, PM, and MRI. Acquisition, analysis, or interpretation of data was contributed by all co-authors. Drafting of the manuscript was performed by LDC, PM, and MRI. Critical revision of the manuscript for important intellectual content was performed by KGS, $J A S, L C, R J R, A G, T B P, J R C, S L B, E B L, N S C, G H$, and MMS. Statistical analysis was done by LDC and LC. The authors read and approved the final manuscript.

\section{Funding}

This research project is supported by cooperative agreement U01 NS041588 co-funded by the National Institute of Neurological Disorders and Stroke (NINDS) and the National Institute on Aging (NIA), National Institutes of Health, Department of Health and Human Service. Representatives of the funding agency have been involved in the review of the manuscript but not directly involved in the collection, management, analysis, or interpretation of the data. Additional support was provided by grants R01 HL080477 and K24 HL111154 from the National Heart, Lung, and Blood Institute (NHLBI).

\section{Availability of data and materials}

All data that support the findings of this study are included in the article or uploaded as supplementary information.

\section{Ethics approval and consent to participate}

The University of Alabama at Birmingham Institutional Review Board and the CMS approved all analyses and waived the requirement to obtain informed consent in the Medicare cohort. All REGARDS study participants provided written informed consent, including for the analysis of their Medicare claims.

\section{Consent for publication}

Not applicable.

\section{Competing interests}

KGS receives research support from Horizon, Takeda, Ironwood, and Sobi and serves as a consultant/advisor for Sobi, Ironwood, Horizon, and Takeda. JAS received consultant fees from Crealta/Horizon, Fidia, UBM LLC, Medscape, WebMD, the National Institutes of Health $(<\$ 10,000$ total each) and the American College of Rheumatology ( $>\$ 10,000$ total); is member of the Executive Committee of Outcome Measures in Rheumatology (OMERACT); and is a stockholder of Amarin pharmaceuticals and Viking therapeutics. EBL, MMS, and PM receive research support from Amgen. EBL also served as a consultant/advisor for Amgen and Novartis. The remaining authors have no disclosures.

\section{Author details}

'Department of Epidemiology, University of Alabama at Birmingham, 1720 2nd Ave South, RPHB 527C, Birmingham, AL 35294-0013, USA. ²Division of Clinical Immunology and Rheumatology, University of Alabama at Birmingham, Birmingham, AL, USA. ${ }^{3}$ Birmingham Veterans Affairs Medical 
Center, Birmingham, AL, USA. ${ }^{4}$ Department of Medicine, Larner College of Medicine at the University of Vermont, Burlington, VT, USA. ${ }^{5}$ Department of Biostatistics, University of Alabama at Birmingham, Birmingham, AL, USA. ${ }^{6}$ Department of Medicine, Weill Cornell Medical College, New York, NY, USA.

\section{Received: 28 September 2019 Accepted: 31 March 2020} Published online: 16 April 2020

\section{References}

1. Khanna D, Fitzgerald JD, Khanna PP, Bae S, Singh MK, Neogi T, Pillinger MH, Merill J, Lee S, Prakash S, et al. 2012 American College of Rheumatology guidelines for management of gout. Part 1: systematic nonpharmacologic and pharmacologic therapeutic approaches to hyperuricemia. Arthritis Care Res. 2012;64(10):1431-46.

2. Liu SC, Xia L, Zhang J, Lu XH, Hu DK, Zhang HT, Li HJ. Gout and risk of myocardial infarction: a systematic review and meta-analysis of cohort studies. PLoS One. 2015;10(7):e0134088.

3. Kim SY, Guevara JP, Kim KM, Choi HK, Heitjan DF, Albert DA. Hyperuricemia and risk of stroke: a systematic review and meta-analysis. Arthritis Rheum. 2009;61(7):885-92.

4. Singh JA, Ramachandaran R, Yu S, Yang S, Xie F, Yun H, Zhang J, Curtis JR. Is gout a risk equivalent to diabetes for stroke and myocardial infarction? A retrospective claims database study. Arthritis Res Ther. 2017;19(1):228.

5. Ho JE, Lyass A, Lee DS, Vasan RS, Kannel WB, Larson MG, Levy D. Predictors of new-onset heart failure: differences in preserved versus reduced ejection fraction. Circ Heart Fail. 2013:6(2):279-86.

6. Howard VJ, Cushman M, Pulley L, Gomez CR, Go RC, Prineas RJ, Graham A, Moy CS, Howard G. The REasons for Geographic And Racial Differences in Stroke Study: objectives and design. Neuroepidemiology. 2005;25(3):135-43.

7. Xie F, Colantonio LD, Curtis JR, Safford MM, Levitan EB, Howard G, Muntner $P$. Linkage of a population-based cohort with primary data collection to Medicare claims: the Reasons for Geographic and Racial Differences in Stroke Study. Am J Epidemiol. 2016;184(7):532-44.

8. Judd SE, Letter AJ, Shikany JM, Roth DL, Newby PK. Dietary patterns derived using exploratory and confirmatory factor analysis are stable and generalizable across race, region, and gender subgroups in the REGARDS study. Front Nutr. 2014;1:29.

9. Traynor K. New gout treatment approved. Am J Health Syst Pharm. 2009; 66(7):606.

10. Singh JA. Veterans affairs databases are accurate for gout-related health care utilization: a validation study. Arthritis Res Ther. 2013;15(6):R224

11. Singh JA, Cleveland JD. Gout and the risk of Parkinson's disease in older adults: a study of U.S. Medicare data. BMC Neurol. 2019;19(1):4.

12. Safford MM, Brown TM, Muntner PM, Durant RW, Glasser S, Halanych JH, Shikany JM, Prineas RJ, Samdarshi T, Bittner VA, et al. Association of race and sex with risk of incident acute coronary heart disease events. JAMA. 2012; 308(17):1768-74.

13. Thygesen K, Alpert JS, White HD, Jaffe AS, Apple FS, Galvani M, Katus HA, Newby LK, Ravkilde J, Chaitman B, et al. Universal definition of myocardial infarction. Circulation. 2007;116(22):2634-53.

14. Luepker RV, Apple FS, Christenson RH, Crow RS, Fortmann SP, Goff D, Goldberg RJ, Hand MM, Jaffe AS, Julian DG, et al. Case definitions for acute coronary heart disease in epidemiology and clinical research studies: a statement from the AHA Council on Epidemiology and Prevention; AHA Statistics Committee; World Heart Federation Council on Epidemiology and Prevention; the European Society of Cardiology Working Group on Epidemiology and Prevention; Centers for Disease Control and Prevention; and the National Heart, Lung, and Blood Institute. Circulation. 2003;108(20): 2543-9.

15. Lara KM, Levitan EB, Gutierrez OM, Shikany JM, Safford MM, Judd SE, Rosenson RS. Dietary patterns and incident heart failure in U.S. adults without known coronary disease. J Am Coll Cardiol. 2019;73(16):2036-45.

16. Butler J, Anker SD, Packer M. Redefining heart failure with a reduced ejection fraction. JAMA. 2019;322(18):1761-2

17. Stroke--1989. Recommendations on stroke prevention, diagnosis, and therapy. Report of the WHO Task Force on Stroke and othe Cerebrovascular Disorders. Stroke. 1989, 20(10):1407-1431.

18. Soliman EZ, Howard G, Cushman M, Kissela B, Kleindorfer D, Le A, Judd S, McClure LA, Howard VJ. Prolongation of QTC and risk of stroke: the REGARDS (REasons for Geographic And Racial Differences in Stroke) study. J Am Coll Cardiol. 2012;59(16):1460-7.
19. White IR, Royston P, Wood AM. Multiple imputation using chained equations: issues and guidance for practice. Stat Med. 2011;30(4):377-99.

20. Lau DT, Briesacher BA, Touchette DR, Stubbings J, Ng JH. Medicare part D and quality of prescription medication use in older adults. Drugs Aging. 2011;28(10):797-807.

21. Krishnan E. Gout and the risk for incident heart failure and systolic dysfunction. BMJ Open. 2012;2(1):e000282.

22. Yancy CW, Jessup M, Bozkurt B, Butler J, Casey DE Jr, Colvin MM, Drazner MH, Filippatos GS, Fonarow GC, Givertz MM, et al. 2017 ACC/AHA/HFSA focused update of the 2013 ACCF/AHA guideline for the management of heart failure: a report of the American College of Cardiology/American Heart Association Task Force on Clinical Practice Guidelines and the Heart Failure Society of America. J Am Coll Cardiol. 2017;70(6):776-803.

23. He J, Ogden LG, Bazzano LA, Vupputuri S, Loria C, Whelton PK. Risk factors for congestive heart failure in US men and women: NHANES I epidemiologic follow-up study. Arch Intern Med. 2001;161(7):996-1002.

24. Kenchaiah S, Evans JC, Levy D, Wilson PW, Benjamin EJ, Larson MG, Kannel WB, Vasan RS. Obesity and the risk of heart failure. N Engl J Med. 2002; 347(5):305-13.

25. Arfe A, Scotti L, Varas-Lorenzo C, Nicotra F, Zambon A, Kollhorst B, Schink T, Garbe $\mathrm{E}$, Herings $\mathrm{R}$, Straatman $\mathrm{H}$, et al. Non-steroidal anti-inflammatory drugs and risk of heart failure in four European countries: nested casecontrol study. BMJ. 2016;354:i4857.

26. Ahmadi SF, Streja E, Zahmatkesh G, Streja D, Kashyap M, Moradi H, Molnar MZ, Reddy U, Amin AN, Kovesdy CP, et al. Reverse epidemiology of traditional cardiovascular risk factors in the geriatric population. J Am Med Dir Assoc. 2015;16(11):933-9.

27. Seminog $\mathrm{OO}$, Goldacre MJ. Gout as a risk factor for myocardial infarction and stroke in England: evidence from record linkage studies. Rheumatology (Oxford). 2013:52(12):2251-9.

28. Kuo CF, Yu KH, See LC, Chou IJ, Ko YS, Chang HC, Chiou MJ, Luo SF. Risk of myocardial infarction among patients with gout: a nationwide populationbased study. Rheumatology (Oxford). 2013;52(1):111-7.

29. Paulus WJ, Tschope C. A novel paradigm for heart failure with preserved ejection fraction: comorbidities drive myocardial dysfunction and remodeling through coronary microvascular endothelial inflammation. J Am Coll Cardiol. 2013;62(4):263-71.

30. Tromp J, Westenbrink BD, Ouwerkerk W, van Veldhuisen DJ, Samani NJ, Ponikowski P, Metra M, Anker SD, Cleland JG, Dickstein K, et al. Identifying pathophysiological mechanisms in heart failure with reduced versus preserved ejection fraction. J Am Coll Cardiol. 2018;72(10):1081-90.

31. Isoda K, Kamezawa Y, Tada N, Sato M, Ohsuzu F. Myocardial hypertrophy in transgenic mice overexpressing human interleukin 1alpha. J Card Fail. 2001; 7(4):355-64.

32. Nishikawa K, Yoshida M, Kusuhara M, Ishigami N, Isoda K, Miyazaki K, Ohsuzu F. Left ventricular hypertrophy in mice with a cardiac-specific overexpression of interleukin-1. Am J Physiol Heart Circ Physiol. 2006;291(1): H176-83.

33. Ingelsson E, Sundstrom J, Arnlov J, Zethelius B, Lind L. Insulin resistance and risk of congestive heart failure. JAMA. 2005;294(3):334-41.

34. Vardeny O, Gupta DK, Claggett B, Burke S, Shah A, Loehr L, RasmussenTorvik L, Selvin E, Chang PP, Aguilar D, et al. Insulin resistance and incident heart failure the ARIC study (Atherosclerosis Risk in Communities). JACC Heart Fail. 2013;1(6):531-6.

35. Ekundayo OJ, Dell'Italia LJ, Sanders PW, Arnett D, Aban I, Love TE, Filippatos G, Anker SD, Lloyd-Jones DM, Bakris G, et al. Association between hyperuricemia and incident heart failure among older adults: a propensitymatched study. Int J Cardiol. 2010;142(3):279-87.

36. Juraschek SP, Tunstall-Pedoe $H$, Woodward M. Serum uric acid and the risk of mortality during 23 years follow-up in the Scottish Heart Health Extended Cohort Study. Atherosclerosis. 2014;233(2):623-9.

37. So A, De Smedt T, Revaz S, Tschopp J. A pilot study of IL-1 inhibition by anakinra in acute gout. Arthritis Res Ther. 2007;9(2):R28.

38. Solomon DH, Glynn RJ, MacFadyen JG, Libby P, Thuren T, Everett BM, Ridker PM. Relationship of interleukin-1 beta blockade with incident gout and serum uric acid levels: exploratory analysis of a randomized controlled trial. Ann Intern Med. 2018;169(8):535-42.

39. Sundy JS, Schumacher HR, Kivitz A, Weinstein SP, Wu R, King-Davis S, Evans RR. Rilonacept for gout flare prevention in patients receiving uric acidlowering therapy: results of RESURGE, a phase III, international safety study. J Rheumatol. 2014;41(8):1703-11. 
40. Everett BM, Cornel JH, Lainscak M, Anker SD, Abbate A, Thuren T, Libby P, Glynn RJ, Ridker PM. Anti-inflammatory therapy with canakinumab for the prevention of hospitalization for heart failure. Circulation. 2019;139(10):128999.

41. Yoo HG, Lee SI, Chae HJ, Park SJ, Lee YC, Yoo WH. Prevalence of insulin resistance and metabolic syndrome in patients with gouty arthritis. Rheumatol Int. 2011;31(4):485-91.

42. Saag KG, Choi H. Epidemiology, risk factors, and lifestyle modifications for gout. Arthritis Res Ther. 2006;8(Suppl 1):S2

43. Scherbakov N, Bauer M, Sandek A, Szabo T, Topper A, Jankowska EA, Springer J, von Haehling S, Anker SD, Lainscak M, et al. Insulin resistance in heart failure: differences between patients with reduced and preserved left ventricular ejection fraction. Eur J Heart Fail. 2015;17(10):1015-21.

44. Banerjee D, Biggs ML, Mercer L, Mukamal K, Kaplan R, Barzilay J, Kuller L, Kizer JR, Djousse L, Tracy $R$, et al. Insulin resistance and risk of incident heart failure: cardiovascular health study. Circ Heart Fail. 2013;6(3):364-70.

45. Choi HK, Curhan G. Independent impact of gout on mortality and risk for coronary heart disease. Circulation. 2007;1 16(8):894-900.

46. Krishnan E, Svendsen K, Neaton JD, Grandits G, Kuller LH. Long-term cardiovascular mortality among middle-aged men with gout. Arch Intern Med. 2008;168(10):1104-10.

47. Harrold LR, Saag KG, Yood RA, Mikuls TR, Andrade SE, Fouayzi H, Davis J, Chan KA, Raebel MA, Von Worley A, et al. Validity of gout diagnoses in administrative data. Arthritis Rheum. 2007;57(1):103-8.

48. Singh JA, Hodges JS, Toscano JP, Asch SM. Quality of care for gout in the US needs improvement. Arthritis Rheum. 2007;57(5):822-9.

\section{Publisher's Note}

Springer Nature remains neutral with regard to jurisdictional claims in published maps and institutional affiliations.

Ready to submit your research? Choose BMC and benefit from:

- fast, convenient online submission

- thorough peer review by experienced researchers in your field

- rapid publication on acceptance

- support for research data, including large and complex data types

- gold Open Access which fosters wider collaboration and increased citations

- maximum visibility for your research: over $100 \mathrm{M}$ website views per year

At $\mathrm{BMC}$, research is always in progress.

Learn more biomedcentral.com/submissions 